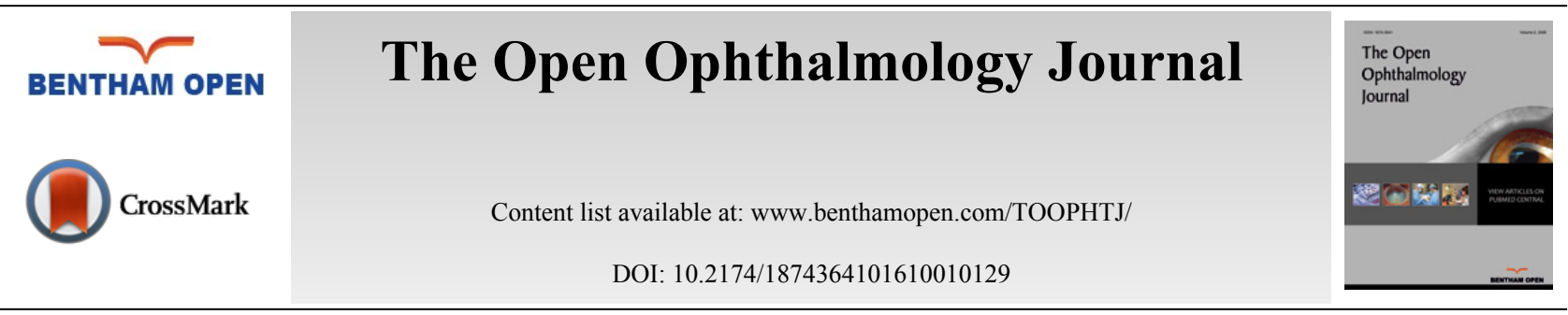

\title{
Risk Factors for Primary Open Angle Glaucoma (POAG) Progression: A Study Ruled in Torino
}

\author{
A.G. Actis $^{1, *}$, E. Versino ${ }^{2}$, B. Brogliatti ${ }^{1}$ and T. Rolle ${ }^{1}$ \\ ${ }^{1}$ University of Torino, Department of Surgical Sciences, Italy \\ ${ }^{2}$ University of Torino, Department of Clinical and Biological Studies, San Luigi Gonzaga Medical School, Italy
}

Received: July 21, 2015

Revised: October 1, 2015

Accepted: October 1, 2015

\section{Abstract:}

Purpose:

Aim of this retrospective, observational study is to describe features of a population sample, affected by primary open angle glaucoma (POAG) in order to evaluate damage progression on the basis of the emerged individual risk factors.

\section{Methods:}

We included 190 caucasian patients (377 eyes), evaluating relationship between individual risk factors (explicative variables) and MD (Mean Deviation) of standard automated perimetry. We also considered the dependent variable NFI (Neural Fiber Index) of GDx scanning laser polarimetry. Progression has been evaluated through a statistic General Linear Model on four follow up steps (mean follow up 79 months).

\section{Results:}

Factors reaching statistical significance, determining a worsening of the MD variable, are: age $(P<0.0001)$, intraocular pressure (IOP) at follow up $(P<0.0001)$, female gender $(P<0.0001)$, hypertension $(P<0.0001)$ and familiarity $(P=0.0006)$.

Factors reaching statistical significance, determining a worsening of the NFI variable, are only IOP at follow up $(P=0.0159)$ and depression $(P=0.0104)$.

\section{Conclusion:}

Results of this study confirm and enforce data coming from most recent studies: IOP remains the main risk factor for glaucoma assess and progression; age and familiarity are great risk factors as underlined in the last decades; female sex can be an important risk factors as emerged only in the last years; arterial hypertension should always be evaluated in timing of our clinic follow up.

Keywords: Epidemiology, glaucoma, intraocular pressure (IOP), optic nerve, progression, risk factors, visual field.

\section{INTRODUCTION}

Open angle glaucoma is a progressive neurodegeneration of retinal ganglion cells (RCGs) and their axons characterized by a specific pattern of visual field and optic nerve head damage [1 - 3].

Clinical trials confirmed the importance of intraocular pressure (IOP) in the development and progression of openangle glaucoma, even if evidence suggests the existence of ocular and systemic factors, in addition to IOP, that can be responsible of this development and progression [4 - 6].

Aim of our retrospective, observational study is that to describe features of a population sample, under treatment at

\footnotetext{
* Address correspondence to this author at the Department of Surgical Sciences, Eye Clinic and Doctoral School in Life and Health Sciences Eye Clinic, via Juvarra 19, 10121, Torino, Italy; Tel: +39 392 2259680; Fax: +30 (0) 11 539024; E-mail: alessandro.actis@gmail.com
} 
the Glaucoma Centre of the Ophthalmologic Clinic of Turin University, in order to value the damage progression on the basis of the emerged individual risk factors.

\section{MATERIALS AND METHODS}

This study was performed with the ethical standards laid down in the 1964 Declaration of Helsinki and its later amendments.

In this observational, retrospective study, we included 190 patients (377 eyes) re-examined in the last 18 months (January 2013 - June 2014) under treatment at the Glaucoma Centre of the Eye Clinic of Turin University.

All patients were caucasian, resident in Italy, affected by primary open angle glaucoma (POAG), with repeatable visual field loss and acquired glaucomatous damages to optic nerve head or nerve fiber layer.

The inclusion parameters in the study foresaw:

- presence of regular follow up examinations at our centre with a minimum of two examinations a year for at least three subsequent years;

- presence of at least one yearly visual field test (i.e. at least four assessable perimetrical tests), carried out with the 30-2 or 24-2 SITA (Swedish Interactive Threshold Algoritm) standard program of the Humphrey Field Analyzer (Carl Zeiss Meditec, Dublin, California, USA);

- if present at least three assessable GDx-VCC scanning laser polarimetry (GDx nerve fiber analyzer, Carl Zeiss Meditec Inc., Dublin, CA, USA) examination during the follow up period, with at least one year time distance from each other.

Patients were classified as having POAG when they had a typical glaucomatous visual field and/or a typical abnormal optic nerve head, open angle at gonioscopy, IOP $>21 \mathrm{mmHg}$ with no treatment and no clinically apparent secondary cause for their glaucoma [2].

A glaucomatous visual field defect was defined as:

- three adjacent points depressed by $5 \mathrm{~dB}$, with one of the points depressed by at least $10 \mathrm{~dB}$ or

- two adjacent points depressed by $10 \mathrm{~dB}$ or

- $10 \mathrm{~dB}$ difference across the nasal horizontal meridian in two adjacent points.

None of the points could be edge points unless immediately above or below the nasal horizontal meridian. In addition, visual field testing was considered reliable only when false-negative and false-positive responses were less than $30 \%$ and fixation losses were less than $20 \%$ on HFA. The abnormal optic nerve head classification was based on the presence of an optic rim notch or of diffuse / generalized loss of optic rim tissue, vertical cup/disc diameter ratio asymmetry unexplained by side differences in optic disc size, disc haemorrhage.

GDx data in the considered follow up period were disposable only for 56 patients (112 eyes). We decided to use the NFI (Neural Fiber Index).

The exclusion parameters in the study foresaw:

- lack of data and of an appropriate follow up;

- unsatisfactory IOP compensation during the follow-up such that patients needed surgical intervention or valve or stent implant;

- onset of other ocular pathologies during the follow up period;

- macular dystrophy or maculopathy diagnosis in patients with GDx data;

- patients less than 18 years old;

- pregnant or nursing women;

- inability to understand and/or complete the tests.

The patients with an evolving cataract, such to create in itself a worsening of the visual acuity higher than $3 / 10$ in the whole follow up period, have been excluded.

In order to analyse the sample, we used an anamnestic questionnaire created on purpose for our study, whose compilation was carried out in presence of paramedical staff. 
For the recording of both epidemiological and clinical data we used the program "Glaucoma Management System Database" ( ${ }^{\circ}$ Daniela Paoli, Italia) [7, 8].

This data processing program consists of a database of simple comprehension and offers the possibility to memorize patients data as support for diagnosis and therapy; created to collect the whole patient case history, it allows the access of recent and remote data in real time.

Concerning data extraction it was necessary the use of an additional Access and Excel (Microsoft Corporation, Redmond, WA, USA) programming developed by us.

Glaucomatous progression was defined of the basis of the dependent variable MD (Mean Defect) of the visual field by means of the Generalized Linear Model (GLM) method. We already decided to analyze the dependent variable NFI (Neural Fiber Index) of GDx [9].

The following explicative variables have been taken into consideration: age; gender, male or female; IOP at follow up; pachymetry; myopia $>4$ dioptres; hypothyroidism; diabetes mellitus; hypercholesterolemia; arterial hypertension; use of systemic and/or topical corticosteroids; hypoacusia; haemicrania; vasospasm; ischemic heart disease; smoke; asthma; depression.

We measured IOP in mmHg with Goldmann applanation tonometer; we measured pachymetry as central corneal thickness (CCT) with ultrasound pachymeter. About corticosteroids use we considered an extended time period therapy (more than 15 days in the last 3 months before the follow up considered time).

In statistics, GLM is a flexible generalization of ordinary least squares regression [10, 11]. The term GLM indicates a whole series of techniques for the statistical analysis of data with the aim of predicting the behavior of certain elements while other variables are changing. The aim is to model a phenomenon so as to obtain a law that has general validity and can give indications on the phenomenon itself and be easily used. The general linear model incorporates a number of different statistical models: ANOVA, ANCOVA, MANOVA, MANCOVA, ordinary linear regression, $t$ test and $\mathrm{F}$ test. The GLM generalizes linear regression by allowing the linear model to be related to the response variable via a link function and by allowing the magnitude of the variance of each measurement to be a function of its predicted value. GLMs were formulated by John Nelder and Robert Wedderburn as a way of unifying various other statistical models, including linear regression, logistic regression and Poisson regression. They proposed an iteratively reweighted least squares method for maximum likelihood estimation of the model parameters. Analysis was performed using SAS 9.1 program [12]. The effect of various individual characteristic on MD value at different observation times $(t 0 t 1, t 2$, t3) has been estimated using a general linear model for repetaed measures. The term "repeated measures" as used in this paper refers to multiple responses taken in sequence on the same experimental unit,e.g., a patient. The feature of repeated measures experiments that requires special attention in data analysis is the correlation pattern among the responses on the same patient over time, as every tipical example of a factorial analysis. The model used is $M D=a g e$, gender, IOP , pachymetry, , myopia $>4$ dioptres, hypothyroidism, diabetes mellitus, hypercholesterolemia , arterial hypertension, corticosteroids, hypoacusia, haemicrania, vasospasm, ischemic heart disease, smoke, asthma, depression where MD is the dependent variable and age, gender, IOP... are explicative variables. We already decided to run a model NFI=age, gender: male or female, IOP, pachymetry, , myopia $>4$ dioptres, hypothyroidism, diabetes mellitus, hypercholesterolemia, arterial hypertension, corticosteroids, hypoacusia, haemicrania, vasospasm, ischemic heart disease, smoke, asthma, depression for the 56 patients who had GDx data during all the follow up period. The effect of the explicative variables has been initially tested in statistical univariate analysis; then, only the variables which have shown a significant effect to the univariate analysis have been inserted in the final GLM model.

\section{RESULTS}

190 Caucasian patients (377 eyes) suffering from POAG, 76 males (40\%) and 114 females (60\%) were included.

The average age was equal to $61.49 \pm 9.58$ years $(33.5-87.9)$. The average age among males was $60.1 \pm 8.7$ years and the average age among females was $62.11 \pm 10.1$ years.

The average follow up in our study was of 79 months, equal to 6.58 years.

The question is which are the determinants, chosen among the most significant ones in literature, responsible of the damage progression in patients suffering from POAG.

In the examined sample, factors that reach statistical significance, determining a worsening of the MD variable, are: 
age $(P<0.0001)$, IOP at follow up $(P<0.0001)$, female gender $(P<0.0001)$, hypertension $(P<0.0001)$ and familiarity $(\mathrm{p}=0.0006)$ (Table 1$)$.

Table 1. Result of GLM model with MD variable. [From SAS 9.1 program].

\begin{tabular}{|c|c|c|c|c|c|}
\hline Origin & DF & Sum of squares & Mean square & F value & Pr $>$ F \\
\hline Model & 110 & 0937.89105 & 372.16265 & 10.04 & $<.0001$ \\
\hline Error & 1091 & 40435.66245 & 37.06294 & & \\
\hline Total not corrected & 1201 & 81373.55350 & & & \\
\hline
\end{tabular}

\begin{tabular}{|c|c|c|c|}
\hline R-squared & Coefficient of variation & MSE root & MD mean \\
\hline 0.265808 & -130.0996 & 6.087934 & -4.679442 \\
\hline
\end{tabular}

\begin{tabular}{|c|c|c|c|c|c|}
\hline Origin & DF & SS Type I & Mean square & F value & Pr $>$ F \\
\hline Interc & 1 & 26298.51157 & 26298.51157 & 709.56 & $<.0001$ \\
\hline time & 79 & 6492.16035 & 81.38178 & 2.20 & $<.0001$ \\
\hline age cl & 5 & 2250.54433 & 450.10887 & 12.14 & $<.0001$ \\
\hline iop & 21 & 2727.45848 & 129.87898 & 3.50 & $<.0001$ \\
\hline sex & 1 & 1501.48649 & 1501.48649 & 40.51 & $<.0001$ \\
\hline hypertension & 1 & 1154.476446 & 1154.476446 & 31.15 & $<.0001$ \\
\hline familiarity & 1 & 473.89027 & 473.89207 & 12.79 & $<.0004$ \\
\hline depression & 1 & 102.36332 & 102.36332 & 2.76 & $<.0968$ \\
\hline
\end{tabular}

\begin{tabular}{|c|c|c|c|c|c|}
\hline Origin & DF & SS Type II & Mean square & F value & Pr $>$ F \\
\hline Interc & 1 & 4432.165511 & 4432.165511 & 119.58 & $<.0001$ \\
\hline time & 79 & 5636.033618 & 71.342198 & 1.92 & $<.0001$ \\
\hline age cl & 5 & 1965.695749 & 393.139150 & 10.61 & $<.0001$ \\
\hline iop & 21 & 2069.241142 & 99.821007 & 2.69 & $<.0001$ \\
\hline sex & 1 & 1827.737675 & 1827.737675 & 49.31 & $<.0001$ \\
\hline hypertension & 1 & 1300.542418 & 1300.542418 & 35.09 & $<.0001$ \\
\hline familiarity & 1 & 438.982088 & 438.982088 & 11.84 & $<.0004$ \\
\hline depression & 1 & 102.363315 & 102.363315 & 2.76 & $<.0968$ \\
\hline
\end{tabular}

In the examinated sample, factors that reach statistical significance, determining a worsening of the NFI variable, are only IOP at follow up $(P=0.0159)$ and depression $(P=0.0104)$ (Table 2).

The other parameters taken into consideration do not reach statistical significance.

We also estimated that, on average, for each $\mathrm{mmHg}$ increase in IOP, there is a worsening of MD variable of -8.82 $\mathrm{dB}$, equivalent to $-1.34 \mathrm{~dB}$ per year (Table 3). This datum has been adjusted also for the fact that these are repeated measures over time and for individual characteristics of the patient, so it can really estimate the real effect of the single IOP on the parameter MD in time.

Table 2. Result of GLM model with NFI variable. [From SAS 9.1 program].

\begin{tabular}{|c|c|c|c|c|c|}
\hline Origin & DF & Sum of squares & Mean square & F value & Pr $>$ F \\
\hline Model & 57 & 201694.6569 & 3538.5028 & 12.32 & $<.0001$ \\
\hline Error & 241 & 69235.3431 & 287.2836 & & \\
\hline Total not corrected & 298 & 270930.0000 & & & \\
\hline
\end{tabular}

\begin{tabular}{|c|c|c|c|}
\hline R-squared & Coefficient of variation & MSE root & NFI mean \\
\hline 0.269959 & 69.72576 & 16.94944 & 24.30872 \\
\hline
\end{tabular}

\begin{tabular}{|c|c|c|c|c|c|}
\hline Origin & DF & SS Type I & Mean square & F value & Pr>F \\
\hline Interc & 1 & 176092.4027 & 176092.4027 & 612.96 & $<.0001$ \\
\hline time & 35 & 12842.1444 & 366.9184 & 1.28 & 0.1476 \\
\hline age cl & 5 & 2621.0812 & 524.2162 & 1.82 & 0.1086 \\
\hline
\end{tabular}


(Table 2) contd.....

(Table 2) contd.....
\begin{tabular}{|c|c|c|c|c|c|}
\hline Origin & DF & SS Type I & Mean square & F value & Pr>F \\
\hline iop & 13 & 7772.1127 & 597.8548 & 0.0159 & 1.26 \\
\hline sex & 1 & 361.3364 & 361.3364 & 0.2632 & 0.31 \\
\hline familiarity & 1 & 88.8787 & 88.8787 & 0.5786 & 0.67 \\
\hline depression & 1 & 1916.7008 & 1916.7008 & 0.0104 \\
\hline
\end{tabular}

\begin{tabular}{|c|c|c|c|c|c|}
\hline Origin & DF & SS Type II & Mean square & F value & $\operatorname{Pr}>\mathbf{F}$ \\
\hline Interc & 1 & 25136.38400 & 25136.38400 & 87.50 & $<.0001$ \\
\hline time & 35 & 11574.48773 & 330.69965 & 1.15 & 0.2670 \\
\hline age cl & 5 & 1952.12440 & 390.42488 & 1.36 & 0.2405 \\
\hline iop & 13 & 5939.52624 & 456.88663 & 1.59 & 0.0384 \\
\hline $\operatorname{sex}$ & 1 & 113.59970 & 113.59970 & 0.40 & 0.5301 \\
\hline familiarity & 1 & 187.23025 & 187.23025 & 0.65 & 0.4203 \\
\hline depression & 1 & 1916.70083 & 1916.70083 & 6.67 & 0.0104 \\
\hline
\end{tabular}

Table 3. IOP effect calculation.

\begin{tabular}{|c|c|c|c|}
\hline IOP* & LSMEAN of MD & \multicolumn{2}{c|}{ C.I. 95\% } \\
\hline & -8.820031 & -13.722347 & -6.035749 \\
\hline \multicolumn{3}{|c|}{$*$ Effects for one unit of IOP in $\mathrm{mmHg}$} \\
\hline
\end{tabular}

\section{DISCUSSION}

The aetiology of POAG is still uncertain up to today: hence the importance to carry out new epidemiological studies.

In literature several factors have been indicated as possible risk factors [13]. If we consider studies with a real statistical significance a very few risk factors emerge indeed. The Canadian Glaucoma Study [4] stated that factors leading to a worsening of the MD variable over time are age, female gender, high level of anticardiolipin antibodies and IOP. Subsequent evaluations of the same group particularly emphasized the importance of the age and anticardiolipin antibodies levels [6]. In a recent review Weinreb and Medeiros [14] summarized how the parameters with significance are few: older age, family history of glaucoma, black race, use of systemic or topical corticosteroids, high intraocular pressure.

From literature it is clear that the main risk factor is represented by IOP, already from year 1622 when Richard Banister [15] gave the first accurate description of glaucoma in English language.

The statistical analysis we carried out has indicated that the main risk factor for the onset and the progression of the damage is IOP: in particular each average increasing mmHg in the IOP means an average worsening of the MD variable of $-8.82 \mathrm{~dB}$, equal to $-1.34 \mathrm{~dB}$ a year.

The Early Manifest Glaucoma Trial, EMGT [16] study showed that each increasing mmHg of the IOP creates a possible growth of $10 \%$ in the progression risk. A reduction of the IOP of $25 \%$ obtained through a standardized treatment (laser + betaxolol) allowed a slowdown in the disease progression from $62 \%$ to $45 \%$ after 6 years of follow up. In the end the study indicated the high IOP and the pseudoesfoliatio as the significant risk factors of the progression.

The Canadian Glaucoma Study [4] confirmed how the average IOP at follow up (before demonstrating a progression) was directly proportional to the progression itself. Each mmHg increase of IOP caused a risk increase approximately of $19 \%$ : this progression seemed more pronounced in the vasospastic patients.

Pressure peaks and IOP fluctuations play a decisive role: the Advanced Glaucoma Intervention Study (AGIS) [17] showed the importance of the IOP variability between an examination and the other as risk factor of the damage progression.

Our study indicates also that, once given the diagnosis of POAG, to the age progression corresponds a higher damage progression.

Considering prevalence, the glaucoma risk increasing with the age was noticed in almost all population studies. Some Authors underlined as the real prevalence increase becomes significant after the age of 60 (studies of Ferndale [18], Bedford [19], Dalby [20], Blue Mountains [21], Casteldaccia [22]) or even of 70 (Framingham [23], Baltimora 


\section{[24], Ponza [25]).}

Chaunan [4] identified age as the main predictive independent factor: in this study the subjects older than 60 years presented an incidence of glaucomatous perimetrical defects seven times higher than the one surveyed among the individuals under 40 years.

Coleman and Miglior [26] recently proposed a review dividing the patients in three groups: progression from normal subject to glaucomatous one; progression from subject suffering from ocular hypertension to glaucomatous one; progression of the damage in the suffering subject. In all groups the age resulted to be a statistically significant risk factor.

The same fact comes out from other studies $[4,27,28]$

Concerning gender, if we observe a sample of studies we can deduce that in some of them there is no statistically significant difference, in other studies males seems to be more struck and in other studies the female gender [29].

The Canadian Glaucoma Study [4, 6] surveyed a risk factor in the female sex (HR 1.94 i.c. 1.09-3.46, p value .02), but it surveyed an even higher risk factor in the presence of anti-cardiolipin antibodies (ACA) at high levels (HR 3.86 i.c. 1.60-9.31, $p$ value .003).

Our study confirms how female gender can be associated to an higher damage progression. We can suppose that also hormonal changes typical of females and related to the age itself could be responsible for these data [30, 31].

We also have to remember that cardiovascular risk can be higher in females.

The familiarity nature of glaucoma has been recognized from decades. In some studies, among those the Baltimore Survey, $50 \%$ of the suffering patients had a positive familiarity, suggesting the genetic defect as important for the pathology development [32].

The study carried out in Holland by Wolfs in 1998 surveyed a risk for relatives of first degree of a subject suffering from POAG of $22 \%$ to develop the pathology, against a $2.3 \%$ of the general population checked [33].

Other studies indicate different increase degrees of the risk to develop POAG for the relatives of first degree which go from 3 to 9 times in comparison with those of the normal population $[34,35]$.

Arterial hypertension and ocular hypertension seem to be correlated in several studies. The correlation between arterial hypertension and glaucoma is less clear. Some studies confirm it, others don't confirm this association [36].

The Los Angeles Latino Eye Study [37] recently demonstrated how the relation between glaucoma prevalence and diastolic arterial pressure can be represented through a "U"-chart: the patients on both extremities of the spectrum result to have an increased risk to develop this pathology. This apparent paradox can be explained with two considerations: the first one is that patients are characterized by a low perfusion pressure at the level of the optic nerve head; the second one is that chronic hypertension associated to atherosclerosis determines an increase of the vessels resistance and a compromising of the vascular self-regulation, finally reducing nutritive exchanges at the level of the capillary bed of the optic nerve head.

Leske [38] underlined how different clinical studies had demonstrated a strong correlation between low perfusion pressure and damage progression: also in this case a common factor could be the alteration of the vascular selfregulation.

According to the Blue Mountains Study [21], a low perfusion pressure rises the damage progression speed; also sudden pressure drops during the night, lowering the perfusion pressure, are a risk factor for the damage progression.

The review of Werne of 2008 [39] concluded that the non physiologic PAOS drops during night and in general sudden changes of the perfusion pressure are important risk factors correlated to the development and to the glaucoma progression, even if there is no unanimous agreement in literature.

Joe et al. [40] included instead in their study 54 eyes of 54 patients with diagnosis of Normal Tension Glaucoma, monitoring the PAOS during the night while they were sleeping in their usual position. The patients were so classified in three groups: "non-dippers", "dippers", “over-dippers" according to the decrease degree of the night arterial pressure compared with the diurnal one. The authors created regression models to adjust the data according to age, central corneal thickness (pachimetry), IOP value before the study, pressure parameters. In order to evaluate the onset and the progression of the damage, they used the MD and PSD indexes of the Humphrey visual field, the TSNIT score 
(temporal, superior, nasal, inferior, temporal) and the NFI of the GDx-VCC. This study demonstrated as a nightly reduction of the arterial pressure was directly linked to a damage progression.

Gugleta [41] underlined the importance of the vascular risk factors and of the oxidative stress, concluding that a deep scan of the vascular risk profile has to be carried out in each glaucomatous patient.

Coming back to the present study a lot of supposed risk factors are not reaching statistical significance. They can always play a role, even if considered alone are not the protagonists. For example ischemic heart attack or diabetes can be linked to hypertension or vessel modifications.

Among the non significant factors in our study it is particularly interesting the role of central corneal thickness.

On the basis of the results of the OHTS a lot of importance was given to this parameter, proposing universal tonometric conversion algorithms; actually the weight of this risk factor is still to understand and studies with many samples are necessary to come to definitive conclusions. In particular it is necessary to analyse three aspects: real weight of the pachymetry on the intraocular pressure; link between pachymetry and other factors (is it only a mechanical factor in the applanation with the Goldmann tonometer?); link between the hypotonic therapy and the pachymetry [42 - 44]

We have at disposal several studies aimed to confirm or not an association between hypothyroidism and POAG: these studies have often produced conflicting results [45 - 48] It is already clear the relationship between hyperthyroidism, particularly in Graves-Basedow disease, and IOP [49].

Some studies on population have investigated the possible association between POAG and hypothyroidism, starting with the Blue Mountain Eye Study, [21] which includes 324 patients (8.9\% of the considered population) with thyroid problems of whom 147 (4\% of the considered population) under thyroxin therapy. The POAG prevalence among the patients with thyroid problems was of $4.6 \%$ against $2.8 \%$ of the resting population. Adjusting the data for confounding factors, the result didn't seem to be statistically significant even if there is an increased risk to develop POAG among patients under levothyroxin therapy in comparison with the patients who didn't reveal previous thyroid pathologies.

These results, as underlined by Cross [49], are not completely clear. The recent paper by Haefliger states there we don't' have enough evidence to state a relationship between hypothiroidism and glaucoma [50].

Considering the GDx GLM we decided to construct, IOP remains the only real risk factor reaching significance. Depression datum can be interesting, but it has got some limitations also because it should be re-evaluated for each patient. We believe that during the anamnestic questionnaire under the label "depression" patients should have included different pathologies. For sure we can state that:

- glaucoma seems related to depression, anxiety and sleep disorders in several studies; [51 - 53]

- it is not clear the role of systemic therapies for these pathologies on IOP;

- there is a strong evidence that glaucoma is linked to neurological pathologies, such as Alzheimer disease, that can have also a pathogenetic relationship with depression in elderly [54 - 56].

POAG has important similarities with other neurodegenerative diseases: it has been shown that RCGs and the optic nerve mechanisms of cell death are similar to those of Alzheimer's disease. In particular deposits of $\beta$-amyloid, characteristic of Alzheimer's disease, have recently been implicated in the pathogenesis of glaucoma. Amyloid $\beta 42$ is not soluble and can deposit and lead to apoptosis. Evidence suggests that patients suffering from Alzheimer's disease have a higher incidence and prevalence of glaucoma, as well as patients suffering from glaucoma are characterized by a higher incidence and prevalence Alzheimer's disease.Some studies have also shown that Alzheimer's disease leads to abnormalities in the retina: reduction of the nerve fiber layer (RNLF), venous constriction and decreased blood flow in these veins [57].

Concluding this discussion we would like to underline the relationship between structure (optic nerve and fibers) and function (visual field). First of all we have to state that is much more difficult to talk about progression only with a structural model. This because the relationship between structure and function is not always clear nor immediate [58].

It 's true that usually a thinning of the RNFL precedes somehow a functional damage, but it's not a general rule.

In some patients we can observe a worsening of the structural parameters without then having functional (and so clinical decision) changes. In other patients we can see functional changes without major structural changes [59 - 62]. 
The American Academy of Ophthalmology recently underlined how no OCT (actually the main device used to analyze structure) on US market has got a stand-alone indication for diagnosis of glaucoma [63].

Certainly, it is interesting that IOP remains the only parameter that has a strong significance related to a structural deterioration evaluated with the GDx and with his index NFI on a follow-up of 6.58 years. In clinical practice it is good to rely on multiple tools that assess the structure (HRT, GDx and particularly OCT) in order to have a clear idea of whether or not a progression of the damage.

Our study has got several limitations:

- we should enlarge the population sample, i.e. with a multicentrical study;

- we should improve structural analysis, particularly with a large population sample and an evaluation with OCT;

- we should improve data coming from the anamnestic questionnaire, re-evalutaing some pathologies (i.e. depression);

- we should factor into our analyses time to progression (dividing "fast progressors" and "slow progressors") considering differences between the two groups;

- we should also consider the hypotonizing therapy for each patient, but we have to state that our center follows EGS Guidelines in order to reach for each patients the IOP target and a good tonometric compense.

\section{CONCLUSION}

Results of this study confirm and enforce data coming from most recent studies:

- IOP remains the main risk factor for glaucoma assess and progression;

- age and familiarity are great risk factors as underlined in the last decades;

- female sex can be an important risk factors as emerged only in the last years: this is an important confirmation of the last literature results;

- arterial hypertension can be an important risk factor as widely explained in the present discussion.

This study can underline how in glaucomatous patients a careful clinical history with an internal medicine perspective is now compulsory and a general medical evaluation of the patient is undoubtedly useful: only in this way it is possible to develop a personalized follow up with an appropriate timing.

Glaucoma is still today a mistery but, exactly for this, stimulating for the scientific research: only in a clinical research context we could disclose it in the future defeating in this way the first cause of irreversible blindness worldwide.

\section{CONFLICT OF INTEREST}

The authors confirm that this article content has no conflict of interest.

\section{ACKNOWLEDGEMENTS}

Declared none.

\section{REFERENCES}

[1] Gandolfi S. Il Glaucoma. Roma, Italia: Mattioli Editore 2005.

[2] European Glaucoma Society. Terminology and guidelines for glaucoma. $3^{\text {rd }}$ ed. Savona: Italia: Dogma Editrice 2008.

[3] Tuulonen A, Airaksinen PJ, Erola E, et al. The finnish evidence-based guideline for open-angle glaucoma. Acta Ophthalmol Scand 2003; 81(1): 3-18. [http://dx.doi.org/10.1034/j.1600-0420.2003.00021.x] [PMID: 12631014]

[4] Chauhan BC, Mikelberg FS, Balaszi AG, LeBlanc RP, Lesk MR, Trope GE. Canadian Glaucoma Study: 2. risk factors for the progression of open-angle glaucoma. Arch Ophthalmol 2008; 126(8): 1030-6. [http://dx.doi.org/10.1001/archopht.126.8.1030] [PMID: 18695095]

[5] Gordon MO, Beiser JA, Brandt JD, et al. The ocular hypertension treatment study: baseline factors that predict the onset of primary openangle glaucoma. Arch Ophthalmol 2002; 120(6): 714-20. [http://dx.doi.org/10.1001/archopht.120.6.714] [PMID: 12049575]

[6] Chauhan BC, Mikelberg FS, Artes PH, et al. Canadian Glaucoma Study: 3. Impact of risk factors and intraocular pressure reduction on the rates of visual field change. Arch Ophthalmol 2010; 128(10): 1249-55. 
[http://dx.doi.org/10.1001/archophthalmol.2010.196] [PMID: 20696979]

[7] Paoli D. Glaucoma Management System Seconda Versione: proceedings of XX AISG Associazione Italiana Studio del Glaucoma, Turin 11-12 March 2005; Edizioni Minerva Medica, Torino (Italia); 2005.

[8] Paoli D. Glaucoma management system software. 2015. Available from: www.glaucomamanagement.eu

[9] Medeiros FA, Zangwill LM, Bowd C, Bernd AS, Weinreb RN. Fourier analysis of scanning laser polarimetry measurements with variable corneal compensation in glaucoma. Invest Ophthalmol Vis Sci 2003; 44(6): 2606-12. [http://dx.doi.org/10.1167/iovs.02-0814] [PMID: 12766063]

[10] Nelder J, Wedderburn R. Generalized linear models. J Joyal Stat Soc Ser A Gen 1972; 135(3): 370-84.

[11] Generalized Linear Model from Med Library.org, 2015. Available from: http://medlibrary.org/medwiki/Generalized_linear_model

[12] Littell RC, Henry PR, Ammerman CB. Statistical analysis of repeated measures data using SAS procedures. J Anim Sci 1998; 76(4): $1216-31$. [PMID: 9581947]

[13] Actis AG, Dall'Orto L, Penna R, Brogliatti B, Rolle T. An internal medicine perspective review of risk factors for assessing and progression of primary open angle glaucoma. Minerva Med 2013; 104(4): 471-85. [PMID: 24008609]

[14] Weinreb RN, Aung T, Medeiros FA. The pathophysiology and treatment of glaucoma: a review. JAMA 2014; 311(18): 1901-11. [http://dx.doi.org/10.1001/jama.2014.3192] [PMID: 24825645]

[15] Barnshaw HD. Great names in the early history of glaucoma. Int Ophthalmol Clin 1979; 19(1): 3-7. [http://dx.doi.org/10.1097/00004397-197901910-00003] [PMID: 376471]

[16] Leske MC, Heijl A, Hussein M, Bengtsson B, Hyman L, Komaroff E. Factors for glaucoma progression and the effect of treatment: the early manifest glaucoma trial. Arch Ophthalmol 2003; 121(1): 48-56. [http://dx.doi.org/10.1001/archopht.121.1.48] [PMID: 12523884]

[17] The Advanced Glaucoma Intervention Study (AGIS): 7. The relationship between control of intraocular pressure and visual field deterioration. Am J Ophthalmol 2000; 130(4): 429-40. [http://dx.doi.org/10.1016/S0002-9394(00)00538-9] [PMID: 11024415]

[18] Hollows FC, Graham PA. Intra-ocular pressure, glaucoma, and glaucoma suspects in a defined population. Br J Ophthalmol 1966; 50(10): 570-86. [http://dx.doi.org/10.1136/bjo.50.10.570] [PMID: 5954089]

[19] Bankes JL, Perkins ES, Tsolakis S, Wright JE. Bedford glaucoma survey. BMJ 1968; 1(5595): 791-6. [http://dx.doi.org/10.1136/bmj.1.5595.791] [PMID: 5641484]

[20] Bengtsson B. The prevalence of glaucoma. Br J Ophthalmol 1981; 65(1): 46-9. [http://dx.doi.org/10.1136/bjo.65.1.46] [PMID: 6969603]

[21] Mitchell P, Smith W, Attebo K, Healey PR. Prevalence of open-angle glaucoma in Australia. The blue mountains eye study. Ophthalmology 1996; 103(10): 1661-9. [http://dx.doi.org/10.1016/S0161-6420(96)30449-1] [PMID: 8874440]

[22] Giuffrè G, Giammanco R, Dardanoni G, Ponte F. Prevalence of glaucoma and distribution of intraocular pressure in a population. The Casteldaccia Eye Study. Acta Ophthalmol Scand 1995; 73(3): 222-5. [http://dx.doi.org/10.1111/j.1600-0420.1995.tb00272.x] [PMID: 7493232]

[23] Kahn HA, Leibowitz HM, Ganley JP, et al. The Framingham Eye Study. I. Outline and major prevalence findings. Am J Epidemiol 1977; 106(1): 17-32. [PMID: 879158]

[24] Tielsch JM, Sommer A, Katz J, et al. Racial variation in the prevalence of primary open angle glaucoma. JAMA 1991; 266(3): 369-74. [http://dx.doi.org/10.1001/jama.1991.03470030069026] [PMID: 2056646]

[25] Cedrone C, Culasso F, Cesareo M, Zapelloni A, Cedrone P, Cerulli L. Prevalence of glaucoma in Ponza, Italy: a comparison with other studies. Ophthalmic Epidemiol 1997; 4(2): 59-72. [http://dx.doi.org/10.3109/09286589709057098] [PMID: 9243650]

[26] Coleman AL, Miglior S. Risk factors for glaucoma onset and progression. Surv Ophthalmol 2008; 53(Suppl. 1): S3-S10. [http://dx.doi.org/10.1016/j.survophthal.2008.08.006] [PMID: 19038621]

[27] Armaly MF, Krueger DE, Maunder L, et al. Biostatistical analysis of the collaborative glaucoma study. I. Summary report of the risk factors for glaucomatous visual-field defects. Arch Ophthalmol 1980; 98(12): 2163-71. [http://dx.doi.org/10.1001/archopht.1980.01020041015002] [PMID: 7447768]

[28] Rivera JL, Bell NP, Feldman RM. Risk factors for primary open angle glaucoma progression: what we know and what we need to know. Curr Opin Ophthalmol 2008; 19(2): 102-6.

[http://dx.doi.org/10.1097/ICU.0b013e3282f493b3] [PMID: 18301282]

[29] Bron A, Chaine G, Villain M, et al. Les facteurs de risque du glaucome primitif à angle ouvert. J Fr Ophtalmol 2008; $31(4)$ : $435-44$. [http://dx.doi.org/10.1016/S0181-5512(08)71443-8] [PMID: 18563046] 
[30] Boles Carenini B, Quaranta CA. L'attendibilità dei mezzi semeiologici nella diagnosi del glaucoma cronico semplice. Roma: Edizioni SOI, Società Oftalmologica Italiana 1977.

[31] Boles Carenini B, Di Bari A. Epidemiologia del glaucoma cronico semplice. Min Oft 1987; 29: 95-122.

[32] Tielsch JM, Sommer A, Katz J, Royall RM, Quigley HA, Javitt J. Racial variations in the prevalence of primary open-angle glaucoma. The Baltimore Eye Survey. JAMA 1991; 266(3): 369-74. [http://dx.doi.org/10.1001/jama.1991.03470030069026] [PMID: 2056646]

[33] Wolfs RC, Klaver CC, Ramrattan RS, van Duijn CM, Hofman A, de Jong PT. Genetic risk of primary open-angle glaucoma. Populationbased familial aggregation study. Arch Ophthalmol 1998; 116(12): 1640-5. [http://dx.doi.org/10.1001/archopht.116.12.1640] [PMID: 9869795]

[34] Wu J, Hewitt AW, Green CM, et al. Disease severity of familial glaucoma compared with sporadic glaucoma. Arch Ophthalmol 2006; 124(7): 950-4. [http://dx.doi.org/10.1001/archopht.124.7.950] [PMID: 16832017]

[35] Weih LM, Nanjan M, McCarty CA, Taylor HR. Prevalence and predictors of open-angle glaucoma: results from the visual impairment project. Ophthalmology 2001; 108(11): 1966-72. [http://dx.doi.org/10.1016/S0161-6420(01)00799-0] [PMID: 11713063]

[36] Actis AG, Dall'Orto L, Penna R, Brogliatti B, Rolle T. An internal medicine perspective review of risk factors for assessing and progression of primary open angle glaucoma. Minerva Med 2013; 104(4): 471-85. [PMID: 24008609]

[37] Memarzadeh F, Ying-Lai M, Chung J, Azen SP, Varma R. Blood pressure, perfusion pressure, and open-angle glaucoma: the Los Angeles Latino Eye Study. Invest Ophthalmol Vis Sci 2010; 51(6): 2872-7. [http://dx.doi.org/10.1167/iovs.08-2956] [PMID: 20089880]

[38] Leske MC, Wu SY, Nemesure B, Hennis A. Incident open-angle glaucoma and blood pressure. Arch Ophthalmol 2002; 120(7): 954-9. [http://dx.doi.org/10.1001/archopht.120.7.954] [PMID: 12096967]

[39] Werne A, Harris A, Moore D, BenZion I, Siesky B. The circadian variations in systemic blood pressure, ocular perfusion pressure, and ocular blood flow: risk factors for glaucoma? Surv Ophthalmol 2008; 53(6): 559-67. [http://dx.doi.org/10.1016/j.survophthal.2008.08.021] [PMID: 19026319]

[40] Joe SG, Choi J, Sung KR, et al. 24 hour blood pressure pattern in patients with NTG in the habitual position. Korean J Ophthalmol 2009; 23(1): 32-9

[http://dx.doi.org/10.3341/kjo.2009.23.1.32] [PMID: 19337477]

[41] Gugleta K. Vascular risk factors in glaucoma - diagnostics. Praxis (Bern 1994) 2009; 98(4): 201-7. [http://dx.doi.org/10.1024/1661-8157.98.4.201] [PMID: 19224488]

[42] Doughty MJ, Gillis N, MacGill J, Montgomery DM. Goldmann tonometry and pachymetry measures in patients with and without topical medical treatment at a glaucoma clinic. Ophthalmic Physiol Opt 2008; 28(6): 558-67. [http://dx.doi.org/10.1111/j.1475-1313.2008.00596.x] [PMID: 19076558]

[43] Kotecha A. What biomechanical properties of the cornea are relevant for the clinician? Surv Ophthalmol 2007; 52(Suppl. 2): S109-14. [http://dx.doi.org/10.1016/j.survophthal.2007.08.004] [PMID: 17998034]

[44] Iester M, Mete M, Figus M, Frezzotti P. Incorporating corneal pachymetry into the management of glaucoma. J Cataract Refract Surg 2009; 35(9): 1623-8. [http://dx.doi.org/10.1016/j.jcrs.2009.05.015] [PMID: 19683164]

[45] Smith KD, Arthurs BP, Saheb N. An association between hypothyroidism and primary open-angle glaucoma. Ophthalmology 1993; 100(10): 1580-4. [http://dx.doi.org/10.1016/S0161-6420(93)31441-7] [PMID: 8414419]

[46] Smith KD, Tevaarwerk GJ, Allen LH. An ocular dynamic study supporting the hypothesis that hypothyroidism is a treatable cause of secondary open-angle glaucoma. Can J Ophthalmol 1992; 27(7): 341-4. [PMID: 1490244]

[47] Tahat AA, al-Khawaldeh AM. Hypothyroidism and open-angle glaucoma: an accidental or an essential coexistence? East Mediterr Health J 2000; 6(2-3): 299-303. [PMID: 11556016]

[48] Girkin CA, McGwin G Jr, McNeal SF, Lee PP, Owsley C. Hypothyroidism and the development of open-angle glaucoma in a male population. Ophthalmology 2004; 111(9): 1649-52. [http://dx.doi.org/10.1016/j.ophtha.2004.05.026] [PMID: 15350317]

[49] Cross JM, Girkin CA, Owsley C, McGwin G Jr. The association between thyroid problems and glaucoma. Br J Ophthalmol 2008; 92(11): 1503-5

[http://dx.doi.org/10.1136/bjo.2008.147165] [PMID: 18927223]

[50] Haefliger IO, von Arx G, Pimentel AR. Pathophysiology of intraocular pressure increase and glaucoma prevalence in thyroid eye disease: a mini-review. Klin Monatsbl Augenheilkd 2010; 227(4): 292-3. [http://dx.doi.org/10.1055/s-0029-1245199] [PMID: 20408077] 
[51] Spinelli D, Faroni E, Castellini G. The “personality" of the glaucomatous patient: preliminary results. Acta Ophthalmol Scand Suppl 1998; 227(227): 53-4. [PMID: 9972350]

[52] Agorastos A, Skevas C, Matthaei M, et al. Depression, anxiety, and disturbed sleep in glaucoma. J Neuropsychiatry Clin Neurosci 2013; 25(3): 205-13. [http://dx.doi.org/10.1176/appi.neuropsych.12020030] [PMID: 24026713]

[53] Zhou C, Qian S, Wu P, Qiu C. Anxiety and depression in Chinese patients with glaucoma: sociodemographic, clinical, and self-reported correlates. J Psychosom Res 2013; 75(1): 75-82.

[http://dx.doi.org/10.1016/j.jpsychores.2013.03.005] [PMID: 23751243]

[54] Bazin N, Bratu L. Depression in the elderly: prodroma or risk factor for dementia? A critical review of the literature. Geriatr Psychol Neuropsychiatr Vieil 2014; 12(3): 289-97. [PMID: 25245315]

[55] Yochim BP, Mueller AE, Kane KD, Kahook MY. Prevalence of cognitive impairment, depression, and anxiety symptoms among older adults with glaucoma. J Glaucoma 2012; 21(4): 250-4. [http://dx.doi.org/10.1097/IJG.0b013e3182071b7e] [PMID: 21336151]

[56] Janssen SF, Gorgels TG, Ramdas WD, et al. The vast complexity of primary open angle glaucoma: disease genes, risks, molecular mechanisms and pathobiology. Prog Retin Eye Res 2013; 37: 31-67.

[http://dx.doi.org/10.1016/j.preteyeres.2013.09.001] [PMID: 24055863]

[57] Ghiso JA, Doudevski I, Ritch R, Rostagno AA. Alzheimer's disease and glaucoma: mechanistic similarities and differences. J Glaucoma 2013; 22(Suppl. 5): S36-8. [http://dx.doi.org/10.1097/IJG.0b013e3182934af6] [PMID: 23733125]

[58] Hirooka K, Manabe S, Tenkumo K, Nitta E, Sato S, Tsujikawa A. Use of the structure-function relationship in detecting glaucoma progression in early glaucoma. BMC Ophthalmol 2014; 14(1): 118. [http://dx.doi.org/10.1186/1471-2415-14-118] [PMID: 25281998]

[59] Hood DC, Kardon RH. A framework for comparing structural and functional measures of glaucomatous damage. Prog Retin Eye Res 2007; 26(6): 688-710.

[http://dx.doi.org/10.1016/j.preteyeres.2007.08.001] [PMID: 17889587]

[60] Heijl A, Rossetti L, Goni F. Save Sight Years II Program, Module III Proceedings of Aurora Program, SSY II, Allergan Ophthalmology, Prague 2012.

[61] Jampel HD. Imaging the optic nerve and posterior pole in glaucoma. Ophthalmology 2014; 121(11): $2079-80$. [http://dx.doi.org/10.1016/j.ophtha.2014.07.011] [PMID: 25444943]

[62] Iester M, Mermoud A, Schnyder C. Frequency doubling technique in patients with ocular hypertension and glaucoma: correlation with octopus perimeter indices. Ophthalmology 2000; 107(2): 288-94. [http://dx.doi.org/10.1016/S0161-6420(99)00058-5] [PMID: 10690827]

[63] Iester M, Traverso CE, De Feo F, et al. Correlation between frequency doubling technology and heidelberg retina tomograph. J Glaucoma 2005; 14(5): 368-74.

[http://dx.doi.org/10.1097/01.ijg.0000176937.93143.bf] [PMID: 16148585]

(C) Actis et al.; Licensee Bentham Open.

This is an open access article licensed under the terms of the Creative Commons Attribution-Non-Commercial 4.0 International Public License (CC BY-NC 4.0) (https://creativecommons.org/licenses/by-nc/4.0/legalcode), which permits unrestricted, non-commercial use, distribution and reproduction in any medium, provided the work is properly cited. 